\title{
Genetic modifiers of fetal hemoglobin affect the course of sickle cell disease in patients treated with hydroxyurea
}

Pierre Allard, ${ }^{1}$ Nareen Alhaj,, ${ }^{2}$ Stephan Lobitz,,4, Holger Cario, ${ }^{4,5}$ Andreas Jarisch, ${ }^{4,6}$ Regine Grosse, ${ }^{4,7}$ Lena Oevermann, ${ }^{4,8}$ Dani Hakimeh, ${ }^{4,8}$ Laura Tagliaferri,, ${ }^{1,4}$ Elisabeth Kohne, ${ }^{5}$ Annette Kopp-Schneider, ${ }^{2}$ Andreas E. Kulozik ${ }^{1,4}$ and Joachim B. Kunz ${ }^{1,4}$ for the German Sickle Cell Disease Study Group.§

\footnotetext{
'Department of Pediatric Oncology, Hematology and Immunology, Hopp-Children's Cancer Center (KiTZ) Heidelberg, University of Heidelberg, Heidelberg; ${ }^{2}$ Abteilung Biostatistik, Deutsches Krebsforschungszentrum (DKFZ), Heidelberg; ${ }^{3}$ Gemeinschaftsklinikum Mittelrhein, Kemperhof, Pädiatrische Hämatologie und Onkologie, Koblenz; ${ }^{4} \mathrm{GPOH}$ Konsortium Sichelzellkrankheit; ${ }^{5}$ Universitätsklinikum Ulm, Klinik für Kinder- und Jugendmedizin, Pädiatrische Hämatologie und Onkologie, Ulm; ${ }^{6}$ Klinikum der Johann-Wolfgang-GoetheUniversität, Zentrum für Kinder- und Jugendmedizin, Schwerpunkt Stammzelltransplantation und Immunologie, Frankfurt am Main; ${ }^{7}$ Universitätsklinikum Hamburg-Eppendorf, Zentrum für Geburtshilfe, Kinder- und Jugendmedizin, Klinik und Poliklinik für Pädiatrische Hämatologie und Onkologie, Hamburg and ${ }^{8}$ Charité - Universitätsmedizin Berlin, Campus VirchowKlinikum, Klinik für Pädiatrie m.S. Onkologie/Hämatologie/KMT, Berlin, Germany

$\S A$ list of the members of the Sickle Cell Disease Study Group appears in the Appendix
}

\author{
Correspondence: \\ Joachim Kunz \\ joachim.kunz@med.uni-heidelberg.de \\ Received: $\quad$ April 11, 2021. \\ Accepted: July 29, 2021. \\ Prepublished: October $28,2021$. \\ https://doi.org/10.3324/haematol.2021.278952 \\ @2022 Ferrata Storti Foundation \\ Haematologica material is published under \\ a CC-BY-NC license @ @ $\Theta$
}

\begin{abstract}
The course of sickle cell disease (SCD) is modified by polymorphisms boosting fetal hemoglobin (HbF) synthesis. However, it has remained an open question how these polymorphisms affect patients who are treated with the HbF-inducing drug hydroxyurea/ hydroxycarbamide. The German SCD registry offers the opportunity to answer this question, because $>90 \%$ of patients are treated according to national guidelines recommending the use of hydroxyurea in all patients above 2 years of age. We analyzed the modifying effect of HbF-related genetic polymorphisms in 417 patients with homozygous SCD >2 years old who received hydroxyurea. HbF levels were correlated with higher total hemoglobin levels, lower rates of hemolysis, a lower frequency of painful crises and of red blood cell transfusions. The minor alleles of the polymorphisms in the $\gamma$-globin promoter (rs7482144), BCL11A (rs1427407) and HMIP (rs66650371) were strongly associated with increased HbF levels. However, these associations did not translate into lower frequencies of vaso-occlusive events which did not differ between patients either carrying or not carrying the HMIP and BCL11A polymorphisms. Patients on hydroxyurea carrying the $\gamma$-globin promoter polymorphism demonstrated substantially higher hemoglobin levels $\left(P<10^{-4}\right)$ but also higher frequencies of painful crises and hospitalizations $(P<0.01)$ when compared to patients without this polymorphism. Taken together, these data indicate that the $\gamma$-globin, HMIP and BCL11A polymorphisms correlate with increased HbF in SCD patients on hydroxyurea. While HbF is negatively correlated with the frequency of painful crises and hospitalizations, this was not observed for the presence of known HbF-boosting alleles.
\end{abstract}

\section{Introduction}

Sickle cell disease (SCD) is a multiorgan disorder with a broad spectrum of clinical presentations. While some patients reach adulthood with few symptoms, others die early from complications such as acute anemia, infection or acute chest syndrome. Besides the $\beta$-globin and $\alpha$-globin genotypes, the most important modifier of SCD is the persisting expression of fetal hemoglobin ( $\mathrm{HbF}$ ), a heritable quantitative trait determined mainly by the three loci $B C L 11 A$, HMIP and HBG. While $\alpha$-thalassemia, if co-inherited with the HbS mutation, slows down $\mathrm{HbS}$ polymerization by reducing the cellular hemoglobin concentration, ${ }^{2}$ persisting $\mathrm{HbF}$ can interfere with the polymerization of
HbS. $^{3}$ Genetic modifiers of HbF synthesis have generally shown a beneficial effect on the phenotype of SCD.,2,4,5 However, some studies have yielded conflicting results and most exclusively included patients who did not receive the disease-modifying drug hydroxyurea. ${ }^{5}$ Several studies analyzing the effects of $\alpha$-thalassemia and HbF-modifiers in patients treated with hydroxyurea suggested that the effect of hydroxyurea on laboratory and clinical outcomes largely supersedes the effect of the genetic modifiers. ${ }^{6-13}$ Both the effects of polymorphisms identified by genomewide association studies to modify the phenotype of SCD and the pharmacological effects of hydroxyurea were originally considered to be mediated via the expression and distribution of HbF. ${ }^{14,15}$ Genetic modifiers of HbF synthesis 
generally interfere with the expression or the binding activity of $B C L 11 A$. While this transcription factor is required for the perinatal "hemoglobin switch", its actions are not limited to the $\beta$-globin locus, ${ }^{16}$ leaving room for effects on red blood cells and on the phenotype of SCD that are independent from $\mathrm{HbF}$ expression. Similarly, hydroxyurea does not exclusively target $\mathrm{HbF}$ expression but in addition exerts effects such as myelosuppression and nitric oxide release that may be equally important in ameliorating SCD..$^{77}$

Considering the pleiotropic effects of both genetic modifiers and pharmacotherapy, the association of genetic modifiers with a certain phenotype may vary with the treatment that is applied. Thus, the actual importance of genetic modifiers for the clinical course of SCD needs to be assessed in the context of pharmacological treatment in addition to previous studies in treatment-naïve patients. In Germany, treatment guidelines ${ }^{18}$ encourage the use of hydroxyurea in all symptomatic patients with SCD, starting at the age of 2 years. Therefore, approximately $90 \%$ of patients with homozygous SCD registered in the German SCD registry are prescribed hydroxyurea. ${ }^{19}$ We made use of laboratory and clinical data collected in this registry to identify the effect of genetic modifiers on the phenotype of homozygous SCD. To this end, we selected polymorphisms known to modify either $\mathrm{HbF}$ expression or the phenotype of SCD, to be independent from each other and to be functionally relevant, for instance by altering transcription factor binding. ${ }^{15,20-23}$ We focused on the polymorphisms rs1427407 and rs7606173 in BCL11A, on the 3 bp deletion delCTA rs66650371 in HMIP and on the $X \mathrm{mn} /$ polymorphism in the $\gamma$-globin promoter, rs7482144. The allele BCL11A rs $1427407 \mathrm{~T}$ was associated with increased $\mathrm{HbF}$ in genomewide association studies and was shown to reduce binding of GATA1 and TAL1 to a DNase-hypersensitive site that regulates $B C L 11 A$ expression..$^{20}$ After conditioning for the association with rs1427407, rs7606173 $\mathrm{G}$ is the $B C L 11 A$ allele that remains most significantly associated with high $\mathrm{HbF}$ expression. It is located in a DNase hypersensitive site $7 \mathrm{~kb}$ closer to the $B C L 11 A$ transcription start site than rs1427407. ${ }^{20}$ The deletion of three base pairs, CTA, in HMIP rs66650371 is considered to cause the strong association of the HMIP locus on chr6 with HbF levels by augmenting an enhancer-like activity located between the $H B S 1 L$ and the MYB genes. ${ }^{21}$ The polymorphism in the $\gamma$-globin promoter that creates an $X \mathrm{mnl}$ restriction site, HGB2 rs7482144 A, has long been a candidate for being the HbFboosting sequence within the high-HbF $\beta$-globin haplotypes ('Senegal' and 'Arab-Indian'). ${ }^{24,25}$ Together, polymorphisms in BCL11A, HMIP and the $\gamma$-globin promoter were estimated to explain approximately $22 \%$ of the variability in HbF expression. ${ }^{26}$ In addition, we analyzed the coinheritance of the $\alpha$-thalassemia trait that has been shown in multiple studies to be associated with a reduced risk of cerebrovascular complications, but an increased risk of painful crises. ${ }^{5}$ We restricted our analyses to patients at least 2 years of age with homozygous SCD who are treated with hydroxyurea, independently of the dose used.

\section{Methods}

\section{Patients' recruitment and data collection}

Patients were recruited through the nationwide German SCD registry (NCT03327428) which collects prospective and retrospective data on patients with SCD in Germany. The study was performed according to the Declaration of Helsinki and approved by the institutional review board of the Medical Faculty of Heidelberg University (S 416/2014). Written informed consent was obtained from patients or legal guardians.

The data collected included demographic information, diagnosis and genotype, treatment, laboratory parameters and clinical events. At the time of the data cutoff, May 13, 2020, 425 patients with homozygous SCD from 28 different institutions were enrolled in the registry. Data were analyzed by PA, JK, NA and AK-S. All co-authors had access to all registry data.

Treatment guidelines implemented in 2014 recommend parental education, the use of penicillin prophylaxis at least until the age of 5 years, and annual screening with transcranial Doppler ultrasound starting from 2 until 18 years of age. The use of hydroxyurea is encouraged in all patients with SCD who have ever experienced a painful vaso-occlusive crisis, including mild ones. The recommended starting dose of hydroxyurea is $15 \mathrm{mg} / \mathrm{kg} /$ day for adults and $20 \mathrm{mg} / \mathrm{kg} /$ day for children. In the case of insufficient efficacy, a dose escalation up to the maximum tolerated dose or to $35 \mathrm{mg} / \mathrm{kg} /$ day is recommended.

For the analysis of the frequency and distribution of genetic modifiers, patients with homozygous SCD of all ages and irrespective of treatment were included. Patients with compound heterozygous SCD ( $\mathrm{HbSC}, \mathrm{HbS} / \beta$-thalassemia, others) were excluded. For the analysis of laboratory parameters and complications of SCD, only patients at least 2 years of age and with ongoing treatment with hydroxyurea were considered. Patients' data collected after stem cell transplantation were excluded. Data on complications and treatment of SCD were documented annually, together with routine laboratory parameters (hemoglobin, mean corpuscular volume [MCV], reticulocytes, lactate dehydrogenase [LDH], bilirubin and $\mathrm{HbF}$ ) (Table 1). The laboratory parameters were only considered if the patient had not received red blood cell transfusions within 100 days before the assessment. All laboratory parameters were determined while the patient was on hydroxyurea and followed for clinical complications. If more than one laboratory data point fulfilled these criteria, we used the average of all available data. 
Patients registered by May 13, 2020 were included in the analysis. For the correlation of $\mathrm{HbF}$ with laboratory parameters and clinical course, all patients with available data were analyzed ( $n=193$ to $n=202$ ) (Figures 1 and 2). All patients for whom the complete set of genetic traits of interest ( $\alpha$ thalassemia, HBG2-polymorphism rs7482144, BCL11A polymorphisms rs1427407 and rs7606173, HMIP polymorphism rs66650371) was available in combination with the respective laboratory parameter ( $n=121$ for $\mathrm{HbF}$ to $\mathrm{n}=164$ for $\mathrm{MCV}$ ) (Table 2) were included in the analyses that correlated genetics with laboratory parameters and clinical course.

In order to investigate geographic and ethnic differences in the phenotypic expression of SCD, we categorized patients according to the origins of their parents from one of the three regions Mediterranean Sea, Sub-Saharan Africa and "rest of the world". The last included mainly patients from Iraq $(n=13)$, all other countries contributed at most two patients.

Pain crises were defined as pain requiring pharmacological treatment and hospitalization with no other obvious cause besides SCD. This definition does not include visits in the emergency department that did not result in hospital admission. Clinical events were considered from the first dose of hydroxyurea until last follow-up (median/mean observation period per patient $1.8 / 1.1$ years; range, $0.5-5.3$ years), independently of changes in the hydroxyurea dose. In 313 patients with at least 1 year of follow-up on hydroxyurea, the severity of SCD was graded as "severe" $(n=83)$ if 1.5 or more pain crises requiring hospitalization per year or 0.5 or more episodes of acute chest syndrome (ACS) per year were documented. In addition, any stroke, sepsis, chronic pain or need of chronic red blood cell transfusions occurring on hydroxyurea defined a severe course.

\section{Genetic analysis}

The HBG2-polymorphism rs7482144 was identified by polymerase chain reaction (PCR) amplification (forward primer: ATA GCA CTT CTT ATT TGG AAA CCA A, reverse primer: TGT CTA AGT TGC CTC GAG ACT AAA G), $X m n /$ digestion and restriction fragment length analysis. ${ }^{22}$ The BCL11A polymorphisms (rs1427407 and rs7606173) were analyzed using sequence-specific TaqMan genotyping. ${ }^{20}$ The 3 bp deletion in HMIP (rs66650371) was diagnosed by sequence-specific PCR and agarose gel electrophoresis. ${ }^{21}$ $\alpha$-thalassemia deletions $\left(-\alpha^{3.7},-\alpha^{4.2},-\alpha^{20.5},-\right.$ SEA and -- MED) were detected by PCR and subsequent agarose gel electrophoresis. ${ }^{27}$

\section{Statistical analysis}

To evaluate the effect of $\mathrm{HbF}$ levels on laboratory parameters we used linear model analysis. To obtain approximately normally distributed variables, the values of $\mathrm{LDH}$, bilirubin and reticulocytes were log-transformed. The as- sociation of $\mathrm{HbF}$ and clinical course was analyzed using a Poisson regression. The impact of the combination of single nucleotide polymorphisms on $\mathrm{HbF}$ and on the laboratory parameters was analyzed by linear multivariable regression analysis. The presence of a single nucleotide polymoprhism-variant was coded with 0 (no polymorphism - wildtype), 1 (heterozygous) and 2 (homozygous) for each studied polymorphism. A Poisson regression was used to estimate the contribution of each polymorphism on the clinical course. All statistical analyses were conducted using $R$ version 4.0.2 (The R Foundation for Statistical Computing 2020).

\section{Results}

\section{Patients' characteristics}

We restricted our analysis to patients at least 2 years of age on hydroxyurea, corresponding to $77.6 \%(n=330)$ of all patients with homozygous SCD in the registry. Of all patients with homozygous SCD $(n=425), 19$ were excluded because of young age (<2 years), 36 were excluded because they were not on hydroxyurea, 16 were excluded from the analysis of laboratory parameters because they had received red blood cell transfusions within 100 days before blood sampling, three were excluded because no data prior to allogeneic stem cell transplantation were documented and 13 did not have complete data on clinical complications. The age cut-off was set at 2 years because hydroxyurea is licensed for use in Europe starting at this age and because HbF levels were not correlated with age and sex in this group of patients (Online Supplementary Figures S1 and S2). The mean daily hydroxyurea dose was $23.2 \mathrm{mg} / \mathrm{kg}$ (standard deviation 5.9; range, 7.7-39.0).

Mean $\mathrm{HbF}$ levels among these patients were higher than those reported in hydroxyurea-naïve patients of West African origin ${ }^{28,29}$ and comparable to those in hydroxyureanaïve patients from India. ${ }^{30}$ Most patients had initiated hydroxyurea treatment before they were enrolled in the registry, but in 25 patients paired HbF measurements from before and after initiation of hydroxyurea treatment were available. During hydroxyurea treatment, $\mathrm{HbF}$ was on average 1.8-fold higher than before (mean $\mathrm{HbF} 23.7 \%$ vs. $13.2 \%$, $P<10^{-4}$ (t-test) (Online Supplementary Figure S3).

While $\alpha$-thalassemia deletions and polymorphisms in $B C L 11 A$ were present in at least a third of all patients, the HBG2-polymorphism rs7482144 and the polymorphism rs66650371 in HMIP affected only a minority of 10 to $15 \%$ of patients (Table 1). These less frequent traits were exceedingly rare among patients originating from sub-Saharan Africa but enriched in patients originating from the Mediterranean region (28\% allele frequency for HMIP rs66650371) and from the rest of the world (47\% allele frequency for the HBG2-polymorphism rs7482144) (Online 
Table 1. Patients' characteristics.

\begin{tabular}{|c|c|c|c|}
\hline Variables & $\mathbf{N}$ of patients & Mean \pm SD & Range \\
\hline $\begin{array}{l}\text { Sex } \\
\text { Female } \\
\text { Male }\end{array}$ & $\begin{array}{l}208 \\
209\end{array}$ & & \\
\hline $\begin{array}{l}\text { Age at last observation under } \\
\text { treatment (years) }\end{array}$ & 330 & $12.6 \pm 8.5$ & $2.3-54.1$ \\
\hline $\begin{array}{l}\text { Hematologic parameters in patients on } \\
\text { hydroxyurea } \\
\text { HbF (\%) } \\
\text { Hb (g/dL) } \\
\text { MCV (fL) } \\
\text { Reticulocytes (\%o) } \\
\text { Bilirubin (mg/dL) } \\
\text { LDH (U/L) }\end{array}$ & $\begin{array}{l}208 \\
300 \\
300 \\
279 \\
281 \\
280\end{array}$ & $\begin{array}{c}17.9 \pm 9.5 \\
9.0 \pm 1.5 \\
92.6 \pm 13.6 \\
75.3 \pm 44.1 \\
2.1 \pm 1.5 \\
509.2 \pm 189.4\end{array}$ & $\begin{array}{c}0-46.7 \\
5-14.3 \\
60.6-134.7 \\
12.7-360 \\
0.2-12.5 \\
167-1545\end{array}$ \\
\hline $\begin{array}{l}\text { Region of origin } \\
\text { Sub-Saharan Africa } \\
\text { Mediterranean Sea } \\
\text { Rest of the world* }\end{array}$ & $\begin{array}{c}285 \\
62 \\
25\end{array}$ & & \\
\hline $\begin{array}{l}\alpha-\text { globin-deletions } \\
0 / 1 / 2\end{array}$ & 243 / 107 / 23 & & \\
\hline $\begin{array}{l}\text { BCL11A rs } 1427407 \\
\text { GG / GT / TT }\end{array}$ & 135 / 88 / 15 & & \\
\hline $\begin{array}{l}B C L 11 A \text { rs7606173 } \\
\text { CC / CG / GG }\end{array}$ & $47 / 117 / 74$ & & \\
\hline $\begin{array}{l}\text { HBG2-polymorphism rs7482144 } \\
\text { WT / het. / hom. }\end{array}$ & 207 / 14 / 24 & & \\
\hline $\begin{array}{l}\text { HMIP rs66650371 } 3 \text { bp del } \\
\text { WT / het. / hom. }\end{array}$ & $211 / 23$ / 6 & & \\
\hline $\begin{array}{l}\text { Clinical events while on hydroxyurea***} \\
\text { Pain crises /year } \\
\text { ACS /year } \\
\text { RBC transfusions/year } \\
\text { Hospitalizations/year }\end{array}$ & $\begin{array}{l}299 \\
300 \\
298 \\
298\end{array}$ & $\begin{array}{l}0.7 \pm 1.2 \\
0.1 \pm 0.4 \\
0.4 \pm 1.1 \\
0.9 \pm 1.4\end{array}$ & $\begin{array}{l}0-10 \\
0-3 \\
0-10 \\
0-11\end{array}$ \\
\hline $\begin{array}{l}\text { Severity of SCD while on hydroxyurea } \\
\text { Not severe/severe }\end{array}$ & & $230 / 83$ & \\
\hline
\end{tabular}

$\mathrm{n}$ refers to the number of evaluable patients for each parameter. The data sets of some patients were incomplete, either because of incomplete documentation or because laboratory parameters could not be analyzed as the patient had received a red blood cell transfusion within 100 days before blood sampling. SD: standard deviation; MCV: mean corpuscular volume; LDH: lactate dehydrogenase; WT: wild-type; het.: heterozygous; hom: homozygous; ACS: acute chest syndrome; RBC: red blood cells; SCD: sickle cell disease, * Iraq $n=13$, all others $n \leq 2$. ** No patients with homozygous SCD and deletion of three $\alpha$-globin genes were registered. *** Clinical events were only evaluated in patients with at least 6 months of follow up while on hydroxyurea, age $>2$ years.

Supplementary Table S1). Of note, the minor allele frequencies of these polymorphisms were paralleled by higher levels of $\mathrm{HbF}$ and total hemoglobin in patients not originating from sub-Saharan Africa (Online Supplementary Table S2). As expected for polymorphisms that are differentially enriched in specific ethnicities and, as is the case for the HBG2-polymorphism rs7482144, are linked to the $\mathrm{HbS}$ mutation, the frequency of homozygous carriers of the minor allele significantly $\left(P<10^{-4}\right)$ exceeded that predicted by the Hardy-Weinberg equilibrium. In contrast, $\alpha$ thalassemia deletions were detected significantly more frequently among patients originating from sub-Saharan Africa in comparison to all other patients (allele frequency $25.2 \%$ vs. $\left.7.1 \%, P<10^{-4}\right)$. Compatible with a linkage disequilibrium, both polymorphisms in BCL11A were signifi- cantly associated with each other $\left(P<10^{-4}\right)$. As expected for independently inherited traits, we did not identify any significant associations between polymorphisms in BCL11A and in HMIP or HBG2. However, the polymorphisms that occurred preferentially in the non-sub-Saharan patients, $H M I P$ and HGB2, were significantly associated with each other $\left(P=0.008, \chi^{2}\right.$ test $)$.

\section{High $\mathrm{HbF}$ levels are associated with a milder phenotype of sickle cell disease}

All hematologic parameters tested were strongly associated with $\mathrm{HbF}$ levels (Figure 1). While patients with an $\mathrm{HbF}$ of $5 \%$ had a mean total hemoglobin of $7.9 \mathrm{~g} / \mathrm{dL}$ (MCV 85 $\mathrm{fL}$ ), patients with an $\mathrm{HbF}$ of $25 \%$ had a mean total hemoglobin of $9.4 \mathrm{~g} / \mathrm{dL}$ (MCV $94 \mathrm{fL}$ ). Indicators of hemolysis 

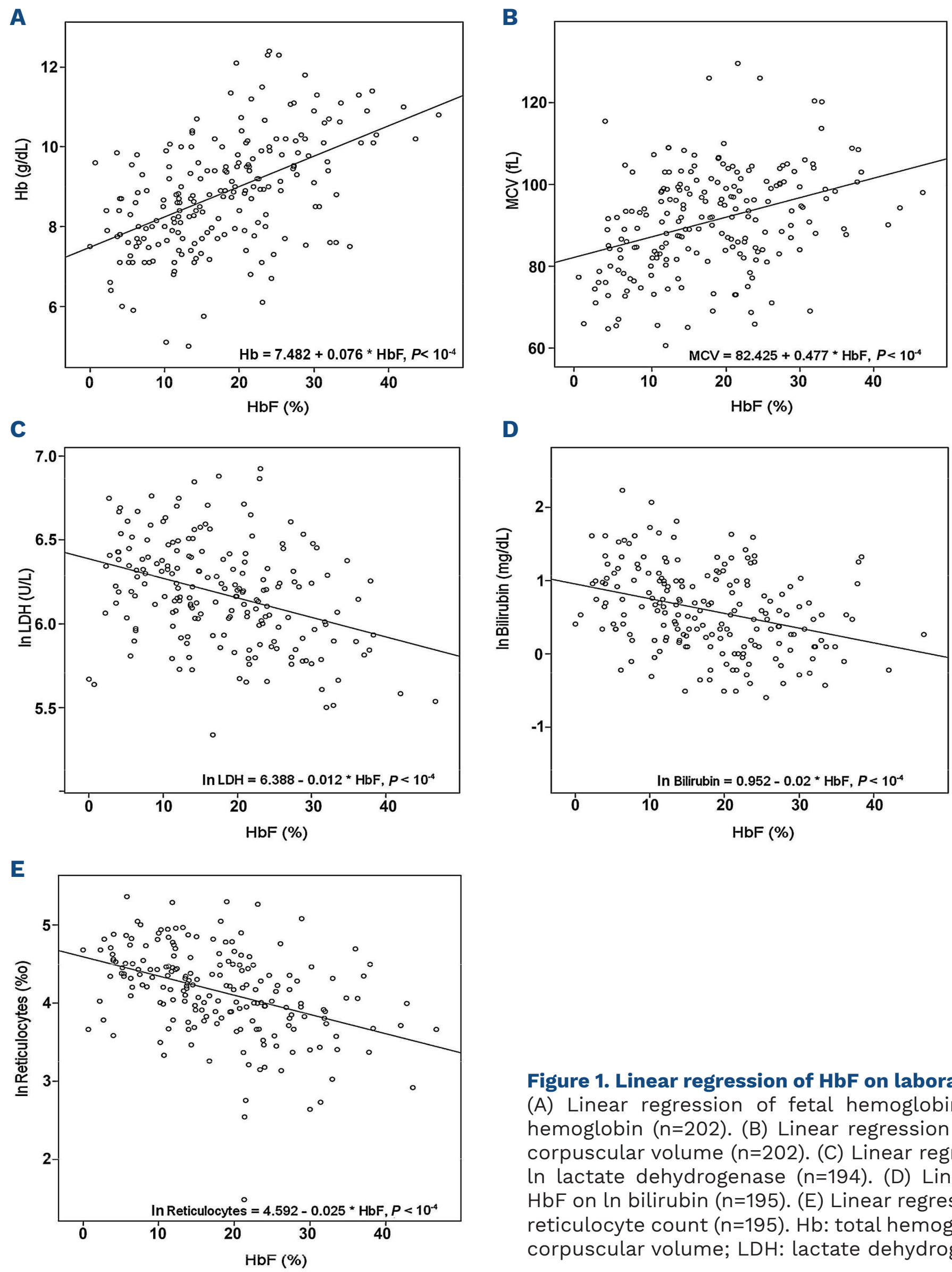

Figure 1. Linear regression of $\mathrm{HbF}$ on laboratory parameters. (A) Linear regression of fetal hemoglobin ( $\mathrm{HbF}$ ) on total hemoglobin $(n=202)$. (B) Linear regression of $\mathrm{HbF}$ on mean corpuscular volume $(n=202)$. (C) Linear regression of $\mathrm{HbF}$ on In lactate dehydrogenase $(n=194)$. (D) Linear regression of $\mathrm{HbF}$ on In bilirubin $(n=195)$. (E) Linear regression of HbF on In reticulocyte count $(n=195)$. Hb: total hemoglobin; MCV; mean corpuscular volume; LDH: lactate dehydrogenase.

showed an inverse relation (patients with $\mathrm{HbF} 5 \%$ vs. 25\%: LDH 560 vs. $441 \mathrm{U} / \mathrm{L}$, bilirubin 2.34 vs. $1.51 \mathrm{mg} / \mathrm{dL}$, reticulocytes $87 \%$ ovs. 53 \%o) (Figure 1).

Simultaneously, the frequency of pain crises and of red blood cell transfusions decreased with increasing $\mathrm{HbF}$ (Figure 2). The frequency of hospitalizations paralleled that of pain crises, reflecting our definition of "pain crisis" as requiring hospitalization and the fact that most admissions in patients with SCD are due to acute pain. In contrast, ACS was not correlated with $\mathrm{HbF}$ levels, indicating a differential effect of $\mathrm{HbF}$ on these complications.
In order to analyze whether adherence to hydroxyurea - reflected by increased MCV, but also HbF and total hemoglobin - is associated with the phenotype, we compared laboratory and clinical parameters in patients with severe SCD to those in patients with non-severe SCD (Online Supplementary Table S3). While severely affected patients were slightly older than non-severely affected patients and carried more HbF-modifying alleles, they did not differ in any other laboratory parameter, most importantly MCV, indicating that potential differences in adherence to hydroxyurea were too small to be detected. 
Table 2. Multivariable analysis of the effect of genetic traits on laboratory parameters and complications of sickle cell disease.

\begin{tabular}{|c|c|c|c|c|c|c|}
\hline & $\begin{array}{l}\alpha- \\
\text { thalassemia }\end{array}$ & $\begin{array}{l}\text { BCL11A } \\
\text { rs1427407 }\end{array}$ & $\begin{array}{l}\text { BCL11A } \\
\text { rs7606173 }\end{array}$ & & $\begin{array}{l}\text { HMIP } \\
\text { rs66650371 }\end{array}$ & $\begin{array}{l}H B G 2 \\
\text { rs7482144 }\end{array}$ \\
\hline $\begin{array}{l}\text { HbF (\%) } \\
(n=121)\end{array}$ & $\begin{array}{l}-1.490 \\
(-4.263- \\
1.282) \\
\end{array}$ & $\begin{array}{l}\mathbf{3 . 8 9 4 ^ { 2 }} \\
(0.939- \\
6.849) \\
\end{array}$ & $\begin{array}{l}-0.403 \\
(-3.013- \\
2.207) \\
\end{array}$ & & $\begin{array}{ll}\mathbf{6 . 0 9 8}^{2} & \\
(0.838- & \uparrow \\
11.359) & \\
\end{array}$ & $\begin{array}{l}2.961^{2} \\
(0.278-\uparrow \\
5.644)\end{array}$ \\
\hline $\begin{array}{l}\text { Mean Hb }(g / d L) \\
(n=163)\end{array}$ & $\begin{array}{l}0.023 \\
(-0.309- \\
0.354)\end{array}$ & $\begin{array}{l}\mathbf{0 . 5 9 7 ^ { 1 }} \\
(0.222- \\
0.972)\end{array}$ & $\begin{array}{l}0.075 \\
(-0.257- \\
0.407)\end{array}$ & & $\begin{array}{l}0.437 \\
(-0.103- \\
0.976)\end{array}$ & $\begin{array}{l}\mathbf{0 . 8 0 7 ^ { 1 }} \\
(0.435- \\
1.180)\end{array}$ \\
\hline $\begin{array}{l}\text { Mean MCV (fL) } \\
(n=164)\end{array}$ & $\begin{array}{l}-9.42^{1} \\
(-12.273- \\
-6.567)\end{array}$ & $\begin{array}{l}3.278^{2} \\
(0.043- \\
6.512)\end{array}$ & $\begin{array}{l}-1.991 \\
(-4.838- \\
0.855)\end{array}$ & & $\begin{array}{l}0.964 \\
(-3.690- \\
5.619)\end{array}$ & $\begin{array}{l}0.731 \\
(-2.481 \\
-3.943)\end{array}$ \\
\hline$(\mathbf{U} / \mathbf{L})$ & \begin{tabular}{ll|}
$-0.075^{3}$ & \\
$(-0.155-\quad \downarrow$ \\
$0.005)$ &
\end{tabular} & $\begin{array}{l}-0.087^{3} \\
(-0.175- \\
0.001)\end{array}$ & $\begin{array}{l}0.067^{3} \\
(-0.011- \\
0.145)\end{array}$ & $\uparrow$ & $\begin{array}{l}-\mathbf{0 . 1 6 0 2} \\
(-0.284-\quad \downarrow \\
-0.036)\end{array}$ & $\begin{array}{l}-0.056 \\
(-0.142 \\
-0.029)\end{array}$ \\
\hline $\begin{array}{l}\text { In Bilirubin } \\
(\mathrm{mg} / \mathrm{dL}) \\
(\mathrm{n}=151)\end{array}$ & $\begin{array}{l}-0.124 \\
(-0.277- \\
0.030)\end{array}$ & $\begin{array}{l}0.061 \\
(-0.106- \\
0.228)\end{array}$ & $\begin{array}{l}0.038 \\
(-0.112- \\
0.187) \\
\end{array}$ & & $\begin{array}{l}-0.391^{1} \\
(-0.629 \\
-0.153\end{array}$ & $\begin{array}{l}0.020 \\
(-0.144 \\
-0.184) \\
\end{array}$ \\
\hline $\begin{array}{l}\text { In Reticulocytes } \\
(\%) \\
(\mathrm{n}=150)\end{array}$ & $\begin{array}{l}-0.232^{1} \\
(-0.362 \\
-0.103)\end{array}$ & $\begin{array}{l}-0.11 \\
(-0.254- \\
0.034)\end{array}$ & $\begin{array}{l}-0.109^{3} \\
(-0.239- \\
0.020) \\
\end{array}$ & $\downarrow$ & $\begin{array}{l}-0.306^{1} \\
(-0.512 \\
-0.101)\end{array}$ & $\begin{array}{l}0.071 \\
(-0.072 \\
-0.214) \\
\end{array}$ \\
\hline $\begin{array}{l}\text { Hospitalizations } \\
\text { (per year) } \\
(\mathrm{n}=161)\end{array}$ & $\begin{array}{l}0.933 \\
(0.764- \\
1.132) \\
\end{array}$ & $\begin{array}{l}0.852 \\
(0.686- \\
1.055) \\
\end{array}$ & $\begin{array}{l}1.194^{3} \\
(0.993- \\
1.438) \\
\end{array}$ & $\uparrow$ & $\begin{array}{l}0.735^{3} \\
(0.497- \\
1.033) \\
\end{array}$ & $\begin{array}{l}1.577^{1} \\
(1.329- \\
1.853) \\
\end{array}$ \\
\hline $\begin{array}{l}\text { Pain crises (per } \\
\text { year) } \\
(n=162)\end{array}$ & $\begin{array}{l}0.959 \\
(0.772- \\
1.181) \\
\end{array}$ & $\begin{array}{l}0.909 \\
(0.719- \\
1.144) \\
\end{array}$ & $\begin{array}{l}1.156 \\
(0.945- \\
1.415) \\
\end{array}$ & & $\begin{array}{l}0.780 \\
(0.519- \\
1.111) \\
\end{array}$ & $\begin{array}{l}1.680^{1} \\
(1.403- \\
1.991) \\
\end{array}$ \\
\hline $\begin{array}{l}\text { ACS (per year) } \\
(n=163)\end{array}$ & $\begin{array}{l}0.589 \\
(0.275- \\
1.119) \\
\end{array}$ & $\begin{array}{l}\mathbf{0 . 4 7 3}^{2} \\
(0.217- \\
0.952) \\
\end{array}$ & $\begin{array}{l}1.646^{3} \\
(0.939- \\
2.942) \\
\end{array}$ & $\uparrow$ & $\begin{array}{l}0.585 \\
(0.101- \\
1.713) \\
\end{array}$ & $\begin{array}{l}1.190 \\
(0.574- \\
2.075)\end{array}$ \\
\hline $\begin{array}{l}\text { Transfusions } \\
\text { (per year) } \\
(\mathrm{n}=163) \\
\end{array}$ & $\begin{array}{l}0.832 \\
(0.579- \\
1.171) \\
\end{array}$ & $\begin{array}{l}1.025 \\
(0.680- \\
1.529) \\
\end{array}$ & $\begin{array}{l}0.907 \\
(0.657- \\
1.248) \\
\end{array}$ & & $\begin{array}{l}\mathbf{0 . 1 1 2} \\
(0.006- \\
0.479) \\
\end{array}$ & $\begin{array}{ll}0.252^{2} & \\
(0.050-\quad \downarrow \\
0.608)\end{array}$ \\
\hline
\end{tabular}

Coefficients (95\% confidence intervals) of a linear regression model are reported for endpoints fetal hemoglobin, total hemoglobin, mean corpuscular volume, lactate dehydrogenase, bilirubin, and reticulocyte count. Positive values indicate a positive correlation, negative values indicate a negative correlation. Exponentiated coefficients (95\% confidence intervals) of Poisson regression are reported for the endpoints hospitalization, pain crises, acute chest syndrome, and transfusions. Values greater than 1 indicate a positive correlation, values smaller than 1 indicate a negative correlation. Blue: positive correlation; red: negative correlation; dark blue/dark red ${ }^{1} P<0.01$; blue/red ${ }^{2} P<0.05$; light blue/ light red $^{3} P<0.1$; all other $P>0.1$; n: number of patients available for analysis HbF: fetal hemoglobin, Hb: total hemoglobin; MCV: mean corpuscular volume; LDH: lactate dehydrogenase; ACS: acute chest syndrome.

\section{Effects of genetic modifiers can be either mediated by $\mathrm{HbF}$ or independent of $\mathrm{HbF}$}

In order to assess whether the effects of genetic modifiers on SCD are mediated by boosting HbF expression, we next compared the correlation of genetic traits with $\mathrm{HbF}$ levels, with laboratory parameters and with complications of SCD (Table 2, Online Supplementary Figures S4-S11, Online Supplementary Tables S4-S7).

As expected, the co-inheritance of $\alpha$-thalassemia resulted in lower MCV and reduced rates of hemolysis without significantly affecting $\mathrm{HbF}$ or total hemoglobin. However, the $\alpha$-thalassemia trait was not linked to the frequency of complications in these patients.

The rarer alleles of the polymorphic loci BCL11A rs1427407, HMIP rs66650371 and HBG2-polymorphism rs7482144 were significantly associated with increased $\mathrm{HbF}$ levels. In addition, the BCL11A rs1427407 and HBG2 rs7482144 polymor- phisms were associated with increased total hemoglobin concentrations. Consistent with this observation, patients carrying the HBG2-polymorphism rs7482144 received red blood cell transfusions less frequently than others. However, neither the increases in $\mathrm{HbF}$ nor those in total hemoglobin were reflected in a reduced frequency of complications of SCD. In contrast, pain crises and hospitalization were strikingly and highly significantly $(P<0.01)$ more frequent in patients carrying the HBG2-polymorphism rs7482144 than in others (Table 2, Figure 3C, D). The coinheritance of two or more HbF-boosting alleles appears to be associated with an additive effect on HbF levels (Online Supplementary Figure S12). While small numbers of patients precluded definitive statistical analyses combining patients' origins and genotypes, the association of rs7482144 with increased $\mathrm{HbF}$ and frequent complications appears to be independent of the region of origin (Online Supplementary Figure S13). 

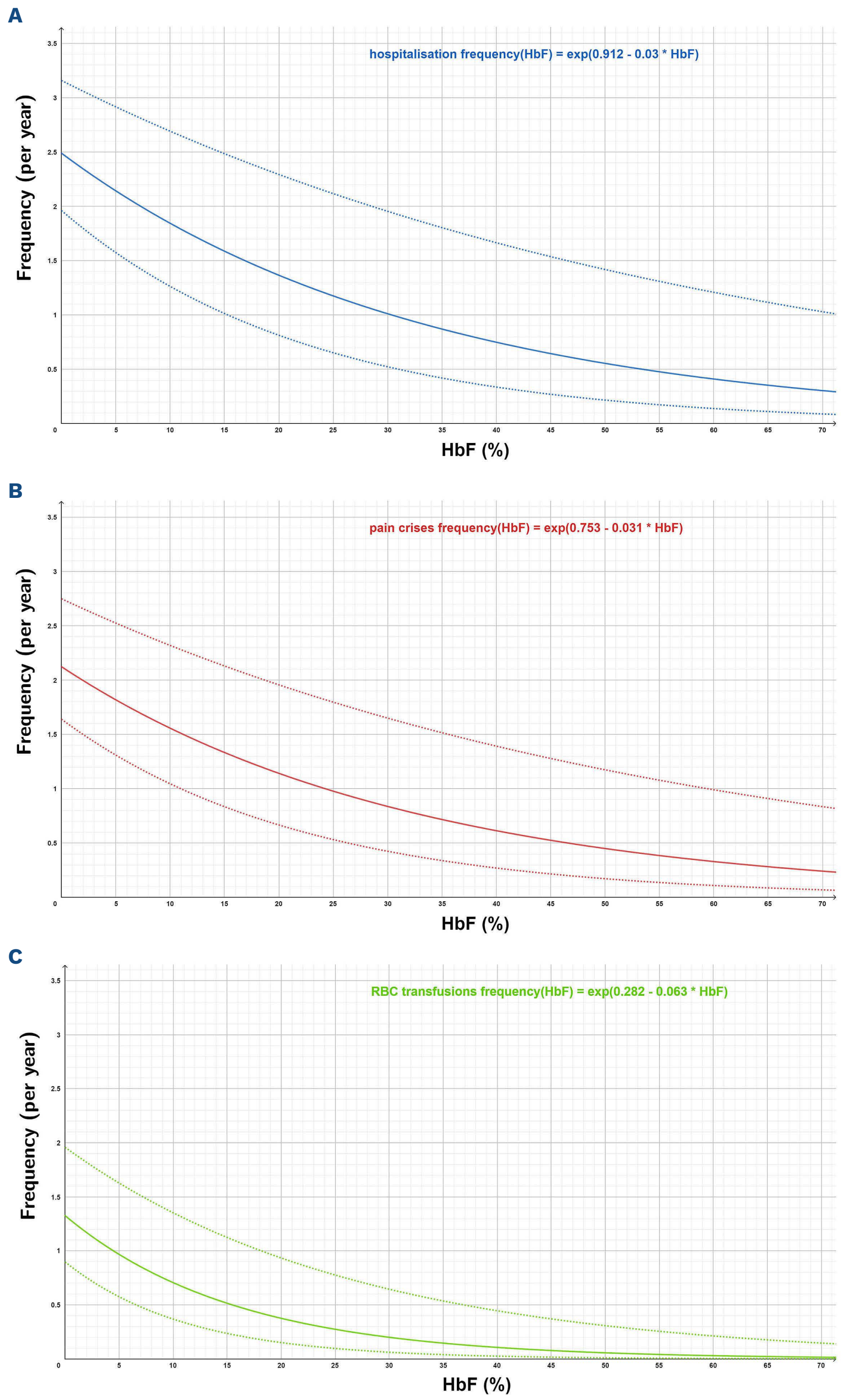

Figure 2. Correlation between HbF level and complications of sickle cell disease. Poisson regression. (A-C) Numbers of patients available for analysis: 193 for hospitalization (A), 194 for pain crises (B), and red blood cell transfusion (C). Thick lines represent the predicted values, thin lines represent the $95 \%$ confidence interval. 
The association of genetic traits with $\mathrm{HbF}$ does not correlate with the association of genetic traits and the rate of hemolysis or the frequency of complications of SCD (Table 2). While decreased LDH levels in patients with BCL11A rs1427407 and HMIP rs66650371 were concordant with increased HbF, BCL11A rs 7606173 was not correlated with $\mathrm{HbF}$ levels but with increased LDH. At the same time, the HBG2polymorphism rs7482144, which was clearly associated with high $\mathrm{HbF}$, was not significantly associated with changes in any of the parameters that are informative of hemolysis. Without having any detectable effect on HbF levels, BCL11A rs7606173 showed a trend towards higher LDH and more frequent hospitalizations and ACS. Although there was no association between increased $\mathrm{HbF}$ and a reduced frequency of ACS, patients carrying BCL11A rs1427407 T showed a significant reduction in the frequency of ACS (Table 2), suggesting an $\mathrm{HbF}$-independent modulation of the SCD phenotype.

We conclude that the induction of HbF expression is only one of several effects that modify the clinical phenotype of SCD in patients treated with hydroxyurea. As BCL11A, a key player that is influenced by polymorphisms in HMIP and $B C L 11 A$ itself, is a pleiotropic transcription factor, its effects will not be limited to the regulation of $\mathrm{HbF}$ expression. In contrast, the HBG2-polymorphism rs7482144 is localized in the $\gamma$-globin promoter and shows a strong association with $\mathrm{HbF}$ but was not correlated with a milder course of SCD in this group of patients on hydroxyurea.

\section{The HBG2-polymorphism rs7482144 defines a group of patients with high risk of painful crises}

As has been observed in several studies of patients not on hydroxyurea, patients on hydroxyurea and with the HBG2polymorphism rs7482144 (heterozygous or homozygous) had significantly higher mean $\mathrm{HbF}(23.6 \pm 8.6 \%$ vs. $17.5 \pm 10 \%$, $P=0.0061)$ (Figure $3 \mathrm{~A}$ ) and mean total hemoglobin (10.1 \pm 1.3 $\mathrm{g} / \mathrm{dL}$ vs. $8.8 \pm 1.4 \mathrm{~g} / \mathrm{dL}, P<10^{-4}$ ) (Figure $3 \mathrm{~B}$ ) when compared to all other patients. At the same time, MCV, reticulocyte counts, bilirubin and LDH levels did not differ between patients who did or did not carry at least one HBG2-polymorphism rs7482144, indicating that the rate of hemolysis is not reduced by the HBG2-polymorphism rs 7482144 . While among patients who did not carry the HBG2-polymorphism rs 7482144 higher levels of $\mathrm{HbF}$ and total hemoglobin were

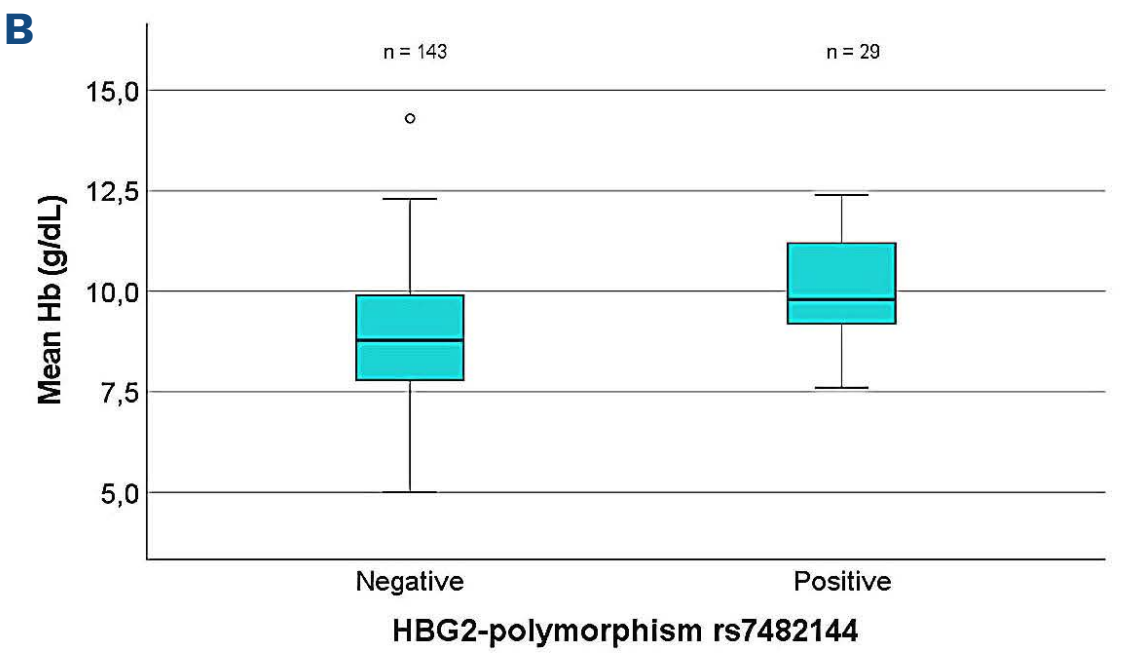

D

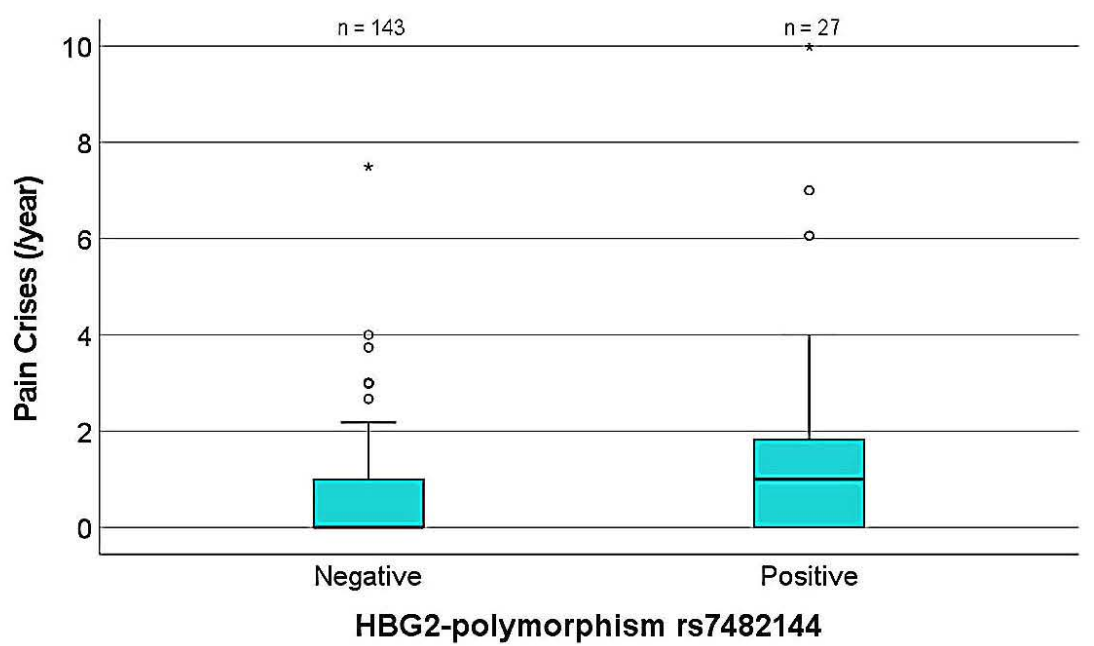

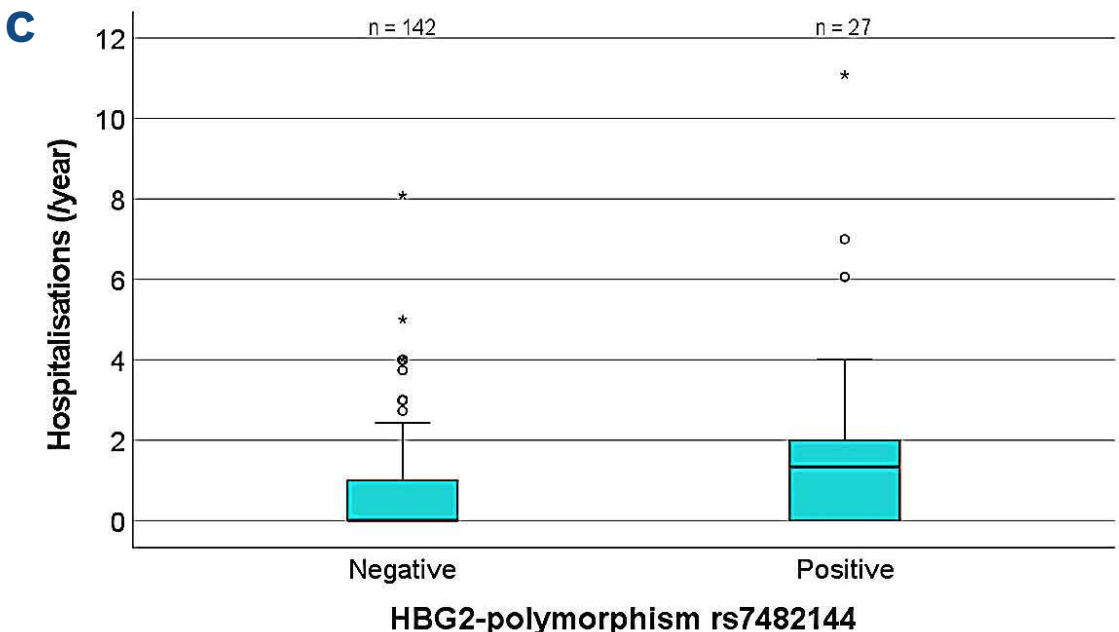

A

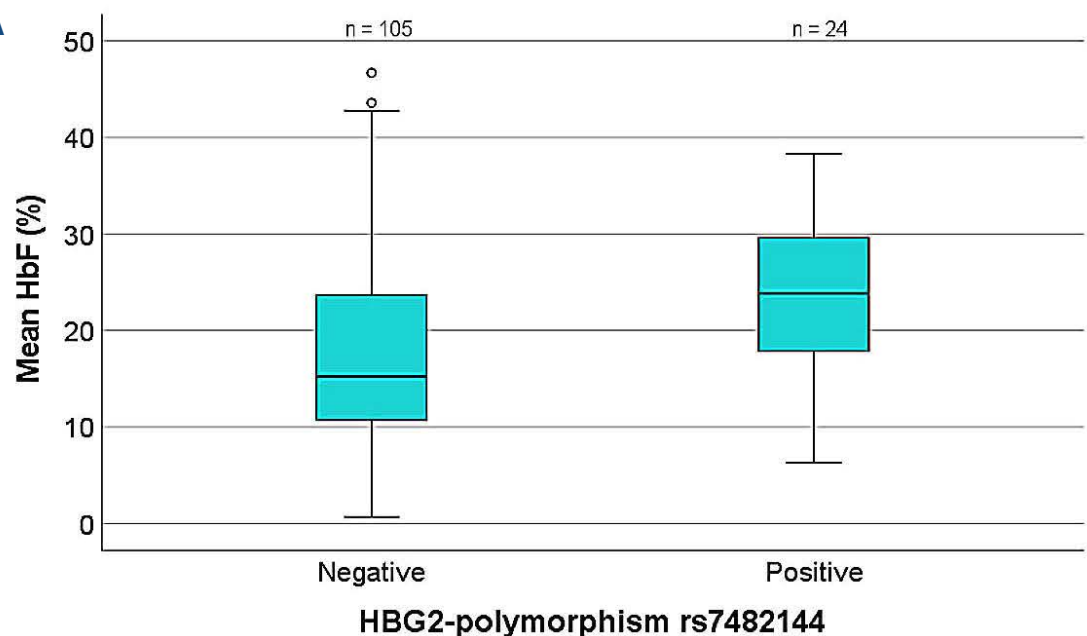

Figure 3. Mean values of laboratory parameters and complications comparing patients positive or negative for the $\gamma$-globin promoter polymorphism rs7482144. (A) Mean HbF \pm standard deviation (SD): negative patients ( $n=105)$ versus positive patients $(n=24): 17.5 \pm 10 \%$ versus $23.6 \pm 8.6 \%$; $t$-test $P=0.0061$. (B) Mean hemoglobin \pm SD: negative patients $(n=143)$ versus positive patients $(\mathrm{n}=29): 8.9 \pm 1.5 \mathrm{~g} / \mathrm{dL}$ versus $10.1 \pm 1.3 \mathrm{~g} / \mathrm{dL}$; $t$-test $P<10^{-4}$. (C) Mean frequency of hospitalizations per year \pm SD: negative patients $(n=142)$ versus positive patients $(n=27): 0.8 \pm 1.3$ versus $1.9 \pm 2.6$; $t$-test $P=0.0011$. (D) Mean frequency of pain crises per year \pm SD: negative patients $(n=143)$ versus positive patients $(n=27)$ : $0.6 \pm 1.1$ versus $1.7 \pm 2.5$; $t$-test $P=0.0003$. HbF: fetal hemoglobin; Hb: total hemoglobin. 
significantly associated with fewer hospitalizations (Online Supplementary Tables S8 and S9), such a correlation was not detected among carriers of the HBG2-polymorphism rs7482144 (Online Supplementary Tables $S 10$ and S11). In contrast, among patients carrying the HBG2-polymorphism rs7482144, there was a slight trend towards a higher total hemoglobin in those who suffered from severe disease $(10.8 \pm 1.6 \mathrm{~g} / \mathrm{dL}$ vs. $10.0 \pm 1.1 \mathrm{~g} / \mathrm{dL}, P=0.21)$. The comparison of hydroxyurea doses prescribed to patients with or without the HBG2-polymorphism rs7482144 A confirmed that hydroxyurea doses were similar in both groups, indicating that the higher rate of complications in patients carrying rs7482144 A was not related to low hydroxyurea doses (Online Supplementary Table S7). In contrast, patients who carried either BCL11A rs1427407 T or HMIP rs66650371 delCTA were prescribed lower doses of hydroxyurea (Online Supplementary Tables S4 and S6), compatible with the notion that the hydroxyurea dose may be titrated according to $\mathrm{HbF}$ response.

\section{Discussion}

The negative correlation between $\mathrm{HbF}$ levels and the frequency of pain crises and of red blood cell transfusions confirms that the $\mathrm{HbF}$ level is a favorable prognostic marker in patients with SCD who are on treatment with hydroxyurea. At the same time, the polymorphisms rs1427407 in BCL11A, rs66650371 in HMIP and rs7482144 in the $\gamma$-globin promoter were strongly correlated with $\mathrm{HbF}$ levels in patients on hydroxyurea, indicating that $\gamma$-globin induction by hydroxyurea did not override the effects of genetic modifiers on HbF levels in this cohort of patients. This observation contrasts with results from trial cohorts that did not identify a significant effect of the genetic modifiers analyzed here on $\mathrm{HbF}$ levels in patients who had been treated with hydroxyurea. ${ }^{6-8,31}$ A possible explanation for this discrepancy may be the younger age of patients in these studies in comparison to our registry patients.

Despite the strong effect of $\mathrm{HbF}$ on the frequency of complications of SCD, the correlation of genetic modifiers with $\mathrm{HbF}$ did not translate into a reduced frequency of pain crises and hospitalizations in those patients who carry HbF-boosting alleles. In contrast, the presence of rs7482144 in the $\gamma$-globin promoter was associated with higher total hemoglobin but, unexpectedly, also with increased frequencies of pain crises and hospitalizations. This is in contrast to several earlier series of patients with SCD not treated with hydroxyurea who carry rs7482144 in the $\gamma$-globin promoter. These patients were characterized by increased $\mathrm{HbF}$ levels $\mathrm{s}^{9,22,32,33}$ and, in contrast to our findings, also less frequent vaso-occlusive events. ${ }^{1,34-37}$ Studies on the association of rs 7482144 with complications of SCD in patients treated with hydroxyurea are scarce. ${ }^{38}$ Consist- ent with our observations, the results of the BABY HUG trial showed a trend towards a higher frequency of vaso-occlusive events in patients who carry rs7482144 if treated with hydroxyurea. ${ }^{6}$ We can only speculate on the reason for the discordant effect of rs7482144 on $\mathrm{HbF}$ and on the frequency of pain crises. Possibly the protective effect of $\mathrm{HbF}$ induction is counterbalanced by the increase in total hemoglobin that results in high blood viscosity and precipitates vasoocclusion. Such an effect would result in an optimal dose level for hydroxycarbamide below the frequently used maximum tolerated dose. Patients presenting with frequent pain episodes despite high $\mathrm{HbF}$ and high total hemoglobin may benefit from a transient reduction of blood viscosity by cautious phlebotomy. Another possible explanation why high $\mathrm{HbF}$ levels and also the HbF-boosting polymorphism BCL11A rs1427407 are associated with a lower frequency of vaso-occlusive complications but rs7482144 in contrast is associated with a higher frequency of vaso-occlusive complications may involve the distribution of $\mathrm{HbF}$. If $\mathrm{HbF}$ were distributed in a heterocellular manner in patients carrying the minor allele of rs7482144, the protection against vaso-occlusive crises would be inferior to that in patients with elevated $\mathrm{HbF}$ that is distributed pancellularly. ${ }^{39}$ As we do not have any data on the cellular distribution of $\mathrm{HbF}$ in our patients, we were not able to test this hypothesis.

The major limitation of our study is the selection of few genetic markers that, with the exception of $\alpha$-thalassemia trait, ${ }^{2}$ focus on the expression of $\mathrm{HbF}^{20-22}$ but do not consider other mechanisms that may modify the phenotype of SCD. ${ }^{40}$ As HbF-boosting polymorphisms are enriched in patients who do not originate from sub-Saharan Africa, we cannot fully discriminate between the effects of single polymorphisms, of the genetic background or even of social and behavioral factors. For future studies, a genome-wide characterization of patients may help in the identification of genetic traits causally related to the phenotype of SCD even in ethnically heterogeneous groups of patients. In addition, we observed a relatively short period of a maximum of 4 years in young patients, who were enrolled in a registry, not in a controlled clinical trial. Because the registry design does not intend source data verification, we do not expect the laboratory parameters and the data on clinical complications to be as complete as in a clinical trial. Similarly, we do not have direct data monitoring patients' adherence to hydroxyurea treatment. However, HbF levels and MCV in these patients were consistently higher than those in hydroxyurea-naïve patients, ${ }^{29,41}$ compatible with a good adherence to treatment in the majority of patients.

The $\gamma$-globin promoter polymorphism rs7482144 was strongly associated with both pain crises and a reduced need for transfusions, indicating that the same genetic trait may have divergent effects on different phenotypic aspects of SCD. This is one reason why general conclusions on the 
course of SCD in an individual patient cannot be drawn from the presence of certain genetic markers. Second, while the genetic signature specifies relative risks in the subgroups, the overlap between subgroups is too large to allow for the prediction of individual risks for complications of SCD. Third, in the present study we only considered acute complications of SCD in a young group of patients but cannot yet evaluate the impact of the polymorphisms on long-term sequelae such as chronic kidney failure or pulmonary hypertension. Therefore, the decision as to whether hydroxyurea or even curative treatment options such as allogeneic stem cell transplantation or gene therapy should be offered cannot be confidently based on the genetic profile analyzed here.

We conclude that polymorphisms in BCL11A, HMIP and $H G B 2$ increase $\mathrm{HbF}$ levels in patients with SCD on hydroxyurea. However, the impact of these polymorphisms on the complications of SCD treated with hydroxyurea was not observed to be correlated with their effect on $\mathrm{HbF}$.

\section{Disclosures}

No conflicts of interest to disclose.

\section{Contributions}

$P A$ collected and analyzed data and wrote the manuscript; $N A$ and $A K-S$ performed statistical analyses; $S L, H C, A J, R G$, $L O, D H, L T$, and $A E K$ designed the study; EK performed genetic analyses; JBK designed and supervised the study, analyzed data and wrote the manuscript; all investigators of the German Sickle Cell Disease Study Group contributed patients' data.

\section{Acknowledgments}

The authors thank Margit Happich and Gabriele Tolle for excellent support with genetic analyses.

\section{Funding}

The German SCD registry is supported by the grants DKS 2016.12 and 2020.03 to JBK from the German Childhood Cancer Foundation.

\section{Data-sharing statement}

The protocol of the SCD registry is available in German language at www.sichelzellkrankheit.info. For original data, please contact joachim.kunz@med.uni-heidelberg.de. As the informed consent does not allow disclosure of individual patients' data, only aggregated data can be provided upon request.

\section{Appendix: Members of the German Sickle Cell Disease Study Group (in alphabetical order)}

Ferras Alashkar, Klinik für Hämatologie, Universitätsklinikum Essen, Essen; Carman Aramayo Singelmann, University Hospital Essen, Pediatric Haematology and Oncology,
Essen; Stefan Balzer, Children's Hospital Amsterdamer Straße Cologne; Clinic for Children and Youth Medicine, Pediatric Oncology/Hematology, Cologne; Ines Brecht, Universitätsklinikum Tübingen, Klinik für Kinder- und Jugendmedizin, Tübingen; Bastian Brummel, Universitätsklinikum Münster, Klinik für Kinder- und Jugendmedizin - Pädiatrische Hämatologie und Onkologie, Münster; Carl Friedrich Classen, Kinder- und Jugendklinik, Universitätsmedizin Rostock, Rostock; Alexander Claviez, Klinik für Kinder- und Jugendmedizin I, Pädiatrische Onkologie, Hämatologie, Stammzelltransplantation, Universitätsklinikum SchleswigHolstein, Campus Kiel; Selim Corbacioglu, Department of Pediatric Hematology, Oncology and Stem Cell Transplantation, University Hospital of Regensburg, Regensburg; Dagmar Dilloo, Pädiatrische Hämatologie und Onkologie, Universitätskinderklinik Bonn, Bonn; Matthias Dürken, Department of Pediatric Hematology and Oncology, University of Mannheim, Mannheim; Wolfgang Eberl, Institute for Clinical Transfusion Medicine and Children's Hospital, Klinikum Braunschweig GmbH;

Sabine Ebert, Abteilung für Pädiatrische Hämatologie und Onkologie, Universitätsklinikum Hamburg-Eppendorf, Hamburg; Miriam Erlacher, Department of Pediatrics and Adolescent Medicine, Division of Pediatric Hematology and Oncology, University Medical Center Freiburg, Faculty of Medicine, University of Freiburg, Freiburg; Gabriele Escherich, Abteilung für Pädiatrische Hämatologie und Onkologie, Universitätsklinikum Hamburg-Eppendorf, Hamburg; Michael Frühwald, University Children's Hospital Augsburg, University Hospital Augsburg, Augsburg; Hermann Full, SLK-Kliniken Heilbronn GmbH, Heilbronn; Ute Groß-Wieltsch, Pediatrics 5 (Oncology, Hematology, Immunology), Center for Pediatric, Adolescent and Women's Medicine, Klinikum Stuttgart - Olgahospital, Stuttgart; Sabine Heine, Department of Pediatric Hematology and Oncology, Saarland University Hospital, Homburg/Saar; Marc Hömberg, Pädiatrische Onkologie und Hämatologie, Universitätsklinikum Köln, Köln; Johannes Holzapfel, University Children's Hospital Augsburg, University Hospital Augsburg, Augsburg; Ursula Holzer, Universitätsklinikum Tübingen, Klinik für Kinder- und Jugendmedizin, Tübingen; Claudia Khurana, Klinik für Kinder- und Jugendmedizin, Evangelisches Klinikum Bethel, Bielefeld; Udo Kontny, Klinik für Kinder- und Jugendmedizin, Universitätsklinikum RWTH Aachen, Aachen; Markus Metzler, Pediatric Oncology and Hematology, Department of Pediatrics and Adolescent Medicine, University Hospital Erlangen, Erlangen; Michaela Nathrath, Zentrum für Frauen- und Kindermedizin, Klinik für Pädiatrische Hämatologie und Onkologie, Kassel; Anna Partheil, Medizinische Hochschule Hannover, Pädiatrische Hämatologie und Onkologie, Hannover; Claudia Maria Pothoff, Pädiatrische Onkologie und Hämatologie, Universitätsklinikum Köln, Köln; Aram Prokop, Helios Kliniken Schwerin, Schwerin; Harald Reinhard, Asklepios Kinderklinik Sankt Augustin, St. Augustin; Daniela 
Schenk, Department of Pediatrics and Children's Cancer Research Center, Kinderklinik München Schwabing, Klinikum rechts der Isar, Fakultät für Medizin, Technische Universität München, Munich; Dominik Schneider, Clinic of Pediatrics, Dortmund Municipal Hospital, Dortmund; Natascha Ströter,
Universitätsklinikum Gießen und Marburg, Standort Gießen, Zentrum für Kinder- und Jugendmedizin, Abteilung für pädiatrische Hämatologie und Onkologie, Gießen; Thomas Wiesel, Children's Hospital, Vestische Youth Hospital, University of Witten/Herdecke, Datteln, Germany.

\section{References}

1. Lettre G, Sankaran VG, Bezerra MA, et al. DNA polymorphisms at the BCL11A, HBS1L-MYB, and beta-globin loci associate with fetal hemoglobin levels and pain crises in sickle cell disease. Proc Natl Acad Sci U S A. 2008;105(33):11869-11874.

2. Higgs DR, Aldridge BE, Lamb J, et al. The interaction of alphathalassemia and homozygous sickle-cell disease. N Engl J Med. 1982;306(24):1441-1446.

3. Singer K, Singer L. Studies on abnormal hemoglobins : VIII. The gelling phenomenon of sickle cell hemoglobin: its biologic and diagnostic significance. Blood. 1953;8(11):1008-1023.

4. Lettre $G$. The search for genetic modifiers of disease severity in the beta-hemoglobinopathies. Cold Spring Harb Perspect Med. 2012;2(10):a015032

5. Meier ER, Fasano RM, Levett PR. A systematic review of the literature for severity predictors in children with sickle cell anemia. Blood Cells Mol Dis. 2017;65:86-94.

6. Sheehan VA, Luo Z, Flanagan JM, et al. Genetic modifiers of sickle cell anemia in the BABY HUG cohort: influence on laboratory and clinical phenotypes. Am $\mathrm{J}$ Hematol. 2013;88(7):571-576.

7. Aleluia MM, Santiago RP, da Guarda CC, et al. Genetic modulation of fetal hemoglobin in hydroxyurea-treated sickle cell anemia. Am J Hematol. 2017;92(5):E70-E72.

8. Sheehan VA, Crosby JR, Sabo A, et al. Whole exome sequencing identifies novel genes for fetal hemoglobin response to hydroxyurea in children with sickle cell anemia. PloS One. 2014;9(10):e110740.

9. Ware RE, Despotovic JM, Mortier NA, et al. Pharmacokinetics, pharmacodynamics, and pharmacogenetics of hydroxyurea treatment for children with sickle cell anemia. Blood. 2011;118(18):4985-4991.

10. Friedrisch JR, Sheehan V, Flanagan JM, et al. The role of BCL11A and HMIP-2 polymorphisms on endogenous and hydroxyurea induced levels of fetal hemoglobin in sickle cell anemia patients from southern Brazil. Blood Cells Mol Dis. 2016;62:32-37.

11. Adekile A, Menzel S, Gupta R, et al. Response to hydroxyurea among Kuwaiti patients with sickle cell disease and elevated baseline HbF levels. Am J Hematol. 2015;90 (7):E138-139.

12. Green NS, Barral S. Genetic modifiers of $\mathrm{HbF}$ and response to hydroxyurea in sickle cell disease. Pediatr Blood Cancer. 2011;56(2):177-181.

13. Green NS, Ender KL, Pashankar F, et al. Candidate sequence variants and fetal hemoglobin in children with sickle cell disease treated with hydroxyurea. PloS One. 2013;8(2):e55709.

14. Dover GJ, Charache S, Boyer SH. Increasing fetal hemoglobin in sickle cell disease: comparisons of 5-azacytidine (subcutaneous or oral) with hydroxyurea. Trans Assoc Am Physicians. 1984;97:140-145.

15. Menzel S, Thein SL. Genetic modifiers of fetal haemoglobin in sickle cell disease. Mol Diagn Ther. 2019;23(2):235-244.

16. Bauer DE, Orkin SH. Hemoglobin switching's surprise: the versatile transcription factor BCL11A is a master repressor of fetal hemoglobin. Curr Opin Genet Dev. 2015;33:62-70.
17. McGann PT, Ware RE. Hydroxyurea for sickle cell anemia: what have we learned and what questions still remain? Curr Opin Hematol. 2011;18(3):158-165.

18. Cario H, Grosse R, Jarisch A, Kulozik AE, Kunz JB, Lobitz S. AWMF-Leitlinie 025/016 Sichelzellkrankheit. 2014.

19. Kunz JB, Lobitz S, Grosse R, et al. Sickle cell disease in Germany: results from a national registry. Pediatr Blood Cancer. 2019;67(4):e28130.

20. Bauer DE, Kamran SC, Lessard S, et al. An erythroid enhancer of $B C L 11 A$ subject to genetic variation determines fetal hemoglobin level. Science. 2013;342(6155):253-257.

21. Farrell JJ, Sherva RM, Chen ZY, et al. A 3-bp deletion in the HBS1L-MYB intergenic region on chromosome $6 q 23$ is associated with HbF expression. Blood. 2011;117(18):4935-4945.

22. Gilman JG, Huisman TH. DNA sequence variation associated with elevated fetal $G$ gamma globin production. Blood. 1985;66(4):783-787.

23. Bhatnagar P, Purvis S, Barron-Casella E, et al. Genome-wide association study identifies genetic variants influencing $\mathrm{F}$-cell levels in sickle-cell patients. J Hum Genet. 2011;56(4):316-323.

24. Labie D, Dunda-Belkhodja O, Rouabhi F, Pagnier J, Ragusa A, Nagel RL. The -158 site 5 ' to the $G$ gamma gene and $G$ gamma expression. Blood. 1985;66(6):1463-1465.

25. Kulozik AE, Kar BC, Satapathy RK, Serjeant BE, Serjeant GR, Weatherall DJ. Fetal hemoglobin levels and beta (s) globin haplotypes in an Indian populations with sickle cell disease. Blood. 1987;69(6):1742-1746.

26. Gardner K, Fulford T, Silver N, et al. $g(\mathrm{HbF})$ : a genetic model of fetal hemoglobin in sickle cell disease. Blood Adv. 2018;2(3):235-239.

27. Bowden DK, Vickers MA, Higgs DR. A PCR-based strategy to detect the common severe determinants of $\alpha$ thalassaemia. $\mathrm{Br} \mathrm{J}$ Haematol. 1992;81(1):104-108.

28. Charache S, Terrin ML, Moore RD, et al. Effect of hydroxyurea on the frequency of painful crises in sickle cell anemia. Investigators of the Multicenter Study of Hydroxyurea in Sickle Cell Anemia. N Engl J Med. 1995;332(20):1317-1322.

29. Borba R, Lima CS, Grotto HZ. Reticulocyte parameters and hemoglobin $\mathrm{F}$ production in sickle cell disease patients undergoing hydroxyurea therapy. J Clin Lab Anal. 2003;17(2):66-72.

30. Kar BC, Satapathy RK, Kulozik AE, et al. Sickle cell disease in Orissa State, India. Lancet. 1986;2(8517):1198-1201.

31. Marahatta A, Flanagan JM, Howard TA, et al. Genetic variants that influence fetal hemoglobin expression from hydroxyurea treatment. Blood. 2020;136(Suppl 1):8-9.

32. Mtatiro SN, Makani J, Mmbando B, Thein SL, Menzel S, Cox SE. Genetic variants at $\mathrm{HbF}$-modifier loci moderate anemia and leukocytosis in sickle cell disease in Tanzania. Am J Hematol. 2015;90(1):E1-4.

33. Nicolau M, Vargas S, Silva M, et al. Genetic modulators of fetal hemoglobin expression and ischemic stroke occurrence in African descendant children with sickle cell anemia. Ann Hematol. 2019;98(12):2673-2681. 
34. Pandey S, Pandey S, Mishra RM, Saxena R. Modulating effect of the -158 gamma (C-->T) Xmn1 polymorphism in Indian sickle cell patients. Mediterr J Hematol Infect Dis. 2012;4(1):e2012001.

35. Gueye Tall F, Martin C, Ndour EHM, et al. Combined and differential effects of alpha-thalassemia and $\mathrm{HbF}$-quantitative trait loci in Senegalese hydroxyurea-free children with sickle cell anemia. Pediatr Blood Cancer. 2019;66(10):e27934.

36. Al-Allawi N, Qadir SMA, Puehringer H, Chui DHK, Farrell JJ, Oberkanins C. The association of HBG2, BCL11A, and HMIP polymorphisms with fetal hemoglobin and clinical phenotype in Iraqi Kurds with sickle cell disease. Int J Lab Hematol. 2018;41(1):87-93.

37. Dadheech S, Jain S, Madhulatha D, et al. Association of Xmn1 -158 gammaG variant with severity and $\mathrm{HbF}$ levels in beta-thalassemia major and sickle cell anaemia. Mol Biol Rep. 2014;41(5):3331-3337.

38. Italia K, Jain D, Gattani S, et al. Hydroxyurea in sickle cell disease--a study of clinico-pharmacological efficacy in the Indian haplotype. Blood Cells Mol Dis. 2009;42(1):25-31.

39. Steinberg MH, Chui DH, Dover GJ, Sebastiani P, Alsultan A. Fetal hemoglobin in sickle cell anemia: a glass half full? Blood. 2014;123(4):481-485.

40. Steinberg MH, Sebastiani P. Genetic modifiers of sickle cell disease. Am J Hematol. 2012;87(8):795-803.

41. Brown AK, Sleeper LA, Miller ST, Pegelow CH, Gill FM, Waclawiw MA. Reference values and hematologic changes from birth to 5 years in patients with sickle cell disease. Cooperative Study of Sickle Cell Disease. Arch Pediatr Adolesc Med. 1994;148(8):796-804. 